\section{Potential confounding in colchicine and cardiovascular disease study}

We appreciate the interest in our recent paper. ${ }^{1}$ As Nielen ${ }^{2}$ notes, we were explicit about potential limitations of the observational methods. The author's suggestion to pick a random index date for non-users is a widely employed method, but we strongly believe that the intensity of healthcare use of colchicine users and non-users should be as similar as possible. This is why we picked an index date for non-users associated with a healthcare visit.

A randomised controlled trial would be the ideal method to examine whether or not colchicine prevents cardiovascular events in patients with gout. While we agree with Nielen that our study may not have ideally balanced potential confounders, this is nearly impossible to achieve (and prove!) in observational studies.

We suggest that the rheumatology community should focus attention on determining the feasibility of a large multi-site colchicine trial among patients with gout. This would be a study that would move the field forward with high-grade evidence.

\section{Daniel H Solomon, ${ }^{1,2}$ Seoyoung C Kim ${ }^{1,2}$}

${ }^{1}$ Division of Rheumatology, Brigham and Women's Hospital, Boston, Massachusetts, USA

${ }^{2}$ Division of Pharmacoepidemiology, Brigham and Women's Hospital, Boston, Massachusetts, USA

Correspondence to Dr Daniel H Solomon, Division of Rheumatology, Brigham and Women's Hospital, 75 Francis Street, Boston MA 02115, USA; dsolomon@partners.org
Funding This work was partially funded by NIH K24 AR055989.

Competing interests DHS receives salary support from unrelated grants to Brigham and Women's Hospital from Lilly, Pfizer and Amgen. DHS and SCK receive research funding from Astra Zeneca on gout that is unrelated to the current paper. SCK receives salary support from unrelated grants to Brigham and Women's Hospital from Lilly and Pfizer.

Provenance and peer review Commissioned; internally peer reviewed.

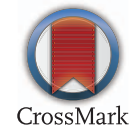

To cite Solomon DH, Kim SC. Ann Rheum Dis 2016;75:e27.

Received 26 January 2016

Accepted 29 January 2016

Published Online First 12 February 2016

\section{S Linked}

http://dx.doi.org/10.1136/annrheumdis-2016-209224

Ann Rheum Dis 2016;75:e27. doi:10.1136/annrheumdis-2016-209242

\section{REFERENCES}

1 Solomon DH, Liu C-C, Kuo I-H, et al. Effects of colchicine on risk of cardiovascular events and mortality among patients with gout: a cohort study using medical records linked with Medicare claims. Ann Rheum Disease 2015; Published Online First: 18 Nov 2015. http://dx.doi.org/10.1136/annrheumdis-2015-207984

2 Nielen J. Effects of colchicine on risk of cardiovascular events and mortality among patients with gout: the effect of index date selection? Ann Rheum Dis 2016;75:e26. 